\title{
cmaJOPEN
}

\section{Injury-related deaths in the Ontario provincial trauma system: a retrospective population-based cohort analysis}

\author{
Christopher C.D. Evans MD MSc, Wenbin Li MSc, Dallas Seitz MD PhD
}

Abstract

Background: Although Ontario has an established trauma system, it experiences a substantial burden of morbidity and mortality from injury. Our objective was to describe patterns of fatal injury in Ontario, with a focus on location of death (out of hospital, trauma or non-trauma centre) and receipt of surgical intervention before death.

Methods: We conducted a retrospective population-based cohort study using linked administrative data on fatal injuries in children and adults (no age restrictions) in Ontario between 2000 and 2016. We identified injury-related deaths in the Ontario Registrar General Death database. We developed descriptive statistics for injury characteristics and causes of death. We calculated the fatal injury incidence rate for each year of the study. The primary outcome was cause of death; the secondary outcome was receipt of surgical intervention.

Results: The analysis included 19408 people. The mean annual incidence of fatal injury averaged 8.7 (95\% confidence interval $7.7-$ 9.6) per 100000 . The most common mechanisms of injury were motor vehicle collisions (12 $065,62.2 \%)$, followed by gunshot wounds $(3134,16.1 \%)$ and falls $(2387,12.3 \%)$. Deaths frequently occurred out of hospital $(72.6 \%)$, rather than at a trauma centre $(14.2 \%)$ or non-trauma centre $(13.2 \%)$. Patients treated at trauma centres were significantly more likely to receive a surgical intervention (standardized difference 0.6 ) than those treated at non-trauma centres.

Interpretation: Most injury deaths in Ontario occur in the out-of-hospital setting or are managed at non-trauma centres; many patients receive no surgical intervention before death. There are likely opportunities to improve access to specialized injury care in Ontario's trauma system.

I n most countries, including Canada, injury remains the leading cause of death in the first 4 decades of life and accounts for more productive years of life lost than any other disease process. ${ }^{1,2}$ People with major trauma experience a $20 \%$ mortality rate, and many survivors are left with permanent disability, ${ }^{3}$ mental health difficulties ${ }^{4-6}$ and a heightened risk of suicide. ${ }^{4}$

In the last several decades, many regions ${ }^{7}$ including Ontario ${ }^{8}$ have developed "trauma systems" to coordinate care for severely injured patients. ${ }^{7-9}$ "Trauma systems" are approached from a public health perspective and aim to provide the full spectrum of trauma care, including rapid emergency medical services response, access to specialist trauma care and rehabilitation programs. ${ }^{10}$

Given that the key function of a trauma system is to reduce injury mortality, it is important to understand the epidemiology of deaths that occur in the system. To date, no studies have described the epidemiology of fatal injury in a Canadian provincial trauma system. Previous studies from the United States have generally been small or regional, with limited generalizability to the Canadian context because of differing patterns of injury (e.g., higher rates of penetrating injuries in the
US), variations in health care system design and socioeconomic factors. ${ }^{11-14}$

Our objective was to describe patterns of fatal injury in Ontario, with a focus on location of death and receipt of surgical intervention before death. We hypothesized that injury deaths would frequently occur outside of trauma centres and in the absence of potentially life-saving surgical intervention.

\section{Methods}

\section{Study design}

We conducted a retrospective, population-based cohort study of fatal injuries from blunt or penetrating trauma in Ontario, Canada, from 2000 to 2016.

Competing interests: None declared.

This article has been peer reviewed.

Correspondence to: Christopher Evans, c.evans@queensu.ca

CMAJ Open 2021. DOI:10.9778/cmajo.20200209 


\section{Setting and sources of data}

Ontario is Canada's most populous province; it has over 14 million inhabitants, ${ }^{15}$ mixed urban, suburban and rural landscapes ${ }^{16}$ and a universal health insurance program (Ontario Health Insurance Program [OHIP]) that ensures access to emergency care services in the province, making it ideally situated for population-based injury research. All unexpected deaths (including injury-related deaths) in Ontario must be reported to the coroner's office, and 90\% of injuryrelated deaths undergo autopsy (Mr. Andrew Stephen, Ontario Coroner's Office, Toronto: personal communication, 2020).

Electronic health data related to OHIP are captured and maintained by ICES, an independent, nonprofit research organization funded by Ontario's Ministry of Health and LongTerm Care. The ICES electronic data holdings include all OHIP-insured health care events for the complete population of Ontario enrolled in OHIP, linked to other data sources using an anonymous unique identifier for each patient.

The ICES data holdings include the National Ambulatory Care Reporting System for visits to emergency departments and the Discharge Abstract Database for inpatient diagnostic and therapeutic information (both managed by the Canadian Institute for Health Information); the Ontario Registrar General Death (ORGD) database for cause-of-death information; and the OHIP database for physician service billing. The ICES databases have been shown to be inclusive of the province's entire emergency system (covering > 99\% of emergency departments), characterized by data linkage rates greater than $95 \%$, and with high internal diagnostic validity (> 90\% compared with medical record abstraction). ${ }^{17,18}$ Injury-specific diagnostic codes have been used to identify patients, exposures and outcomes in many previous ICES studies, ${ }^{4,19,20}$ and injury mechanisms and diagnoses that have been specifically examined for validity have shown highly favourable diagnostic characteristics. ${ }^{21,22}$

\section{Study population}

We identified people of any age who received a fatal injury by searching ORGD records (2000-2016) for deaths associated with both a qualifying Canadian version of the International Statistical Classification of Diseases and Related Health Problems, 10th Revision (ICD-10-CA) External Cause of Injury Code (Appendix 1, available at www.cmajopen.ca/content/9/1/E208/ suppl/DC1) and a qualifying ICD-10-CA (or 9th revision) injury diagnosis code (Appendix 2, available at www.cmajopen. ca/content/9/1/E208/suppl/DC1) recorded in that database. We made the a priori decision to include only people with both types of injury codes, because we anticipated an already large sample size and felt it was more important to have high specificity in identifying injury deaths than to maximize sensitivity.

We prespecified external cause of injury codes to identify mechanisms of injury associated with substantial energy transfer. People who died because of a fall from standing, poisoning, fire, drowning, environmental exposures, acts of war or legal interactions were excluded. We used the National Center for Health Statistics ICD-10 External Cause of Mortality Matrix to summarize the mechanism and intent of injury. ${ }^{23}$ Individuals were excluded if they met any of following criteria: they did not reside in Ontario; they had no ICES number to permit data linkage; or they did not die from an injury due to substantial blunt force or penetrating trauma.

We extracted the following clinical characteristics: age; sex; socioeconomic status and rurality (based on postal codes and the Rurality Index for Ontario ${ }^{24}$ ); patient comorbidities (2-year "look-back" period using the Elixhauser Comorbidity Index score ${ }^{25-27}$ ); causes of injury; injury diagnoses recorded on the death certificate; and aspects of care, including whether the person died in the out-of-hospital or in-hospital setting. In-hospital settings were classified as trauma centres or nontrauma centres based on institutional identification numbers.

For in-hospital deaths, we linked ORGD records to corresponding records in the National Ambulatory Care Reporting System and Discharge Abstract Database to obtain injuryrelated diagnoses and trauma-centre status. We prespecified a number of surgical procedures (Appendix 3, available at www. cmajopen.ca/content/9/1/E208/suppl/DC1) that would be commonly performed for critically injured patients, including laparotomy, thoracotomy and evacuation of intracranial hematoma, and we identified these based on billing codes from the OHIP database. The data sets were linked using unique encoded identifiers and analyzed at ICES.

\section{Outcomes}

The primary outcome was cause of death, including the mechanism of injury (e.g., motor vehicle collision, fall from height, stabbing) and anatomic injury diagnoses (e.g., brain injury, thoracic trauma). Causes of death are described based on location of death (out-of-hospital v. in-hospital) and the type of hospital (trauma centre or non-trauma centre). The secondary outcome calculated only for in-hospital deaths was the percent of patients who received surgical intervention ("receipt of surgery").

\section{Statistical analysis}

We performed cross-tabulations for demographic and baseline variables and descriptive statistics for injury characteristics, causes of death and surgical interventions. We compared baseline and injury characteristics, as well as rates of surgical interventions between care settings using standardized differences. We used standardized differences because they are independent of sample size; this was important because we anticipated finding many differences in characteristics between study groups that were not clinically important but detectable with standard inferential tests based on our large sample size. ${ }^{28,29}$ A standardized difference greater than 0.1 was taken as statistically significant.

We calculated the standardized incidence rate for fatal injuries for each year of the study by counting the number of fatal injuries for the year of study divided by the total population of Ontario for that year; it is reported per 100000 persons. Yearly incidence rates were adjusted for age and sex distribution using the year 2000 as the population reference standard. We used simple linear regression to assess for variation in the standardized fatal injury incidence over the study period. We made no adjustments for missing data because rates of "missingness" were less than $1 \%$ for all variables in the analysis. 


\section{Ethics approval}

The study (TRAQ No. 6027550) was approved by the Health Sciences and Affiliated Teaching Hospitals Research Ethics Board of Queen's University, Kingston, Ontario.

\section{Results}

The final study cohort consisted of 19408 people identified in the ORGD who did not meet any of the exclusion criteria (Figure 1). The annual incidence of fatal injury over the study period averaged 8.7 (95\% confidence interval [CI] 7.7-9.6) per 100000 and varied from a low of 5.5 (95\% CI 5.1-5.9) per 100000 in 2013 to a high of 10.9 (95\% CI 10.3-11.5) per 100000 in 2003 . The annual fatal injury incidence rate varied significantly over the study period ( $p<0.001$; Figure 2$)$.

Most individuals in the study population were male (14529, 74.9\%), with no comorbidities (Elixhauser Comorbidity Index score $=0$ ) and from urban regions of the province $(15112,77.9 \%$; Table 1$)$. The median age was 45 years (interquartile range 26-62 years), with relatively fewer deaths in those under 18 years of age (1301, 6.7\%). Most injuries were accidental (13 250, 68.3\%), and deaths occurred predominately out of hospital (14 089, 72.6\%). Of the 5319 patients treated in hospital, similar proportions of patients were treated in trauma centres $(2761,51.9 \%)$ and nontrauma centres $(2558,48.1 \%)$.

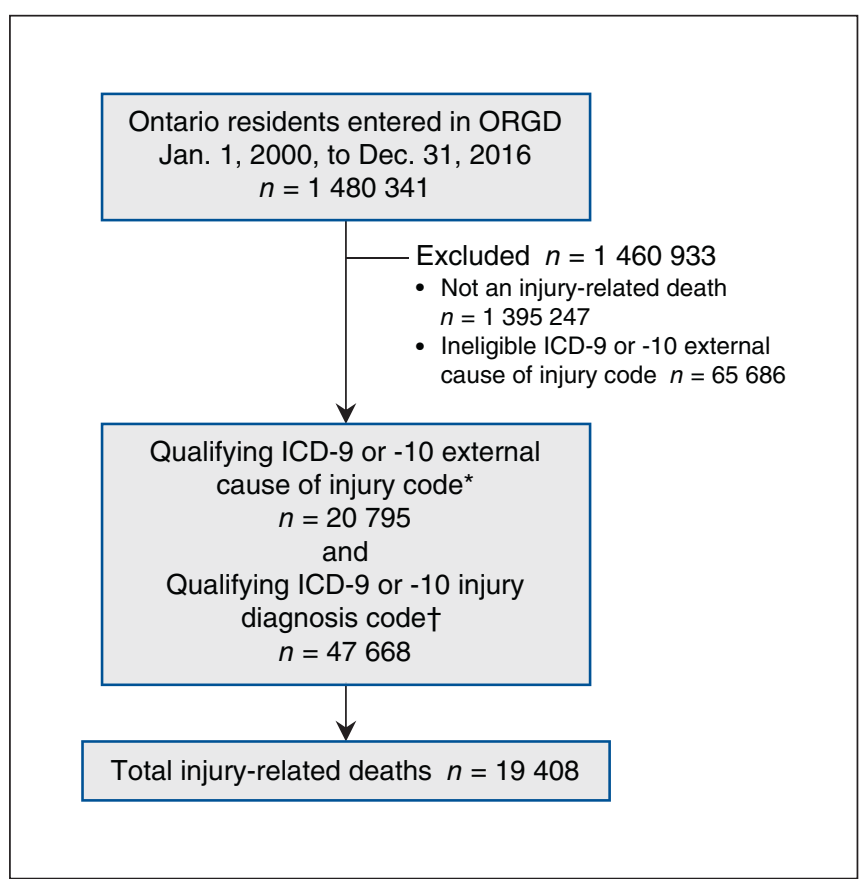

Figure 1: Data-creation flowchart. Note: ICD = International Classification of Diseases, ORGD = Ontario Registrar General Death Database. *Appendix 1, available at www.cmajopen.ca/content/9/1/E208/ suppl/DC1. †Appendix 2, available at www.cmajopen.ca/content/9/1/ E208/suppl/DC1.

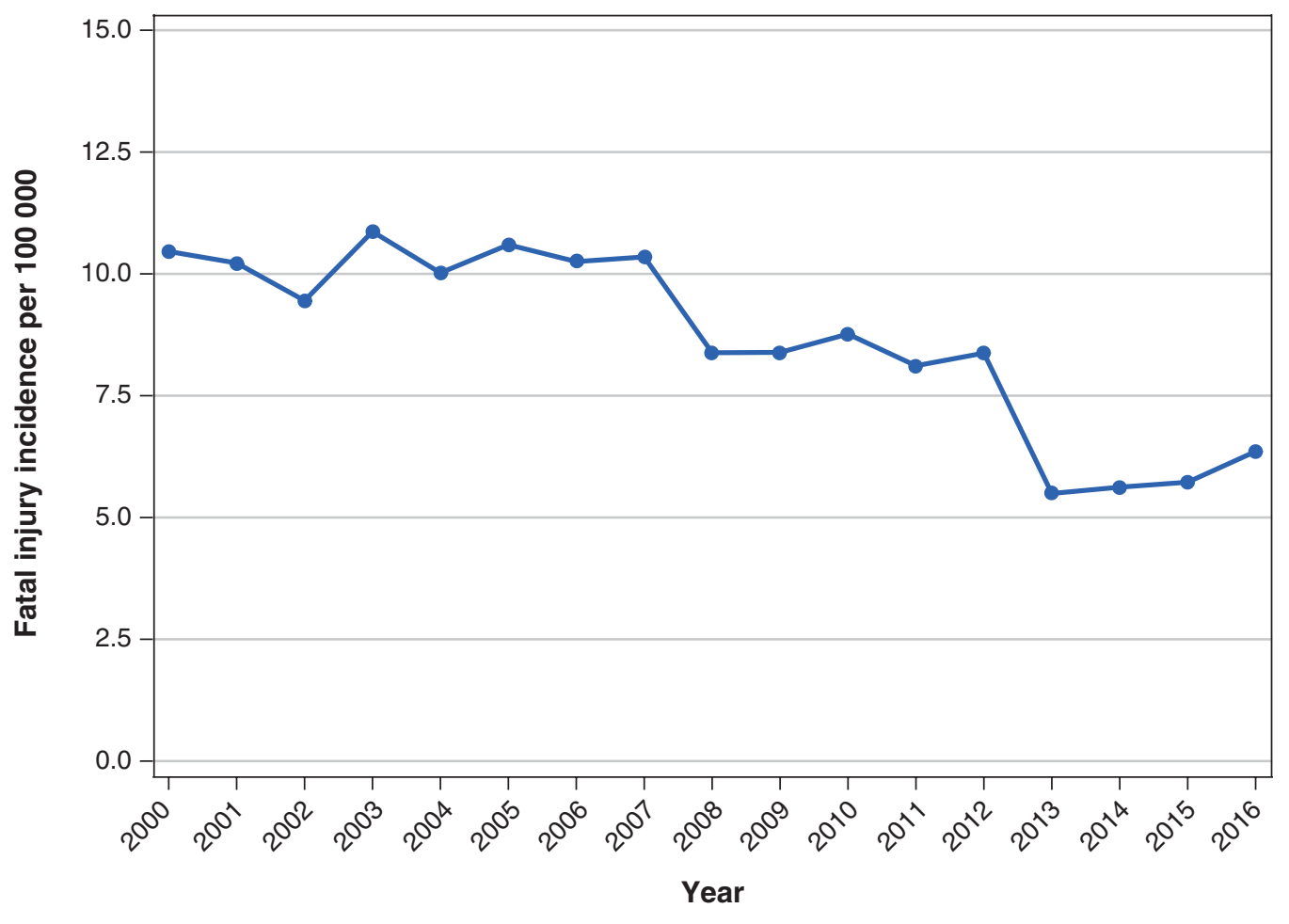

Figure 2: Age- and sex-standardized annual fatal injury incidence in Ontario from 2000 to 2016 . The incidence rate varied significantly over the study period $(p<0.001)$. 


\begin{tabular}{|c|c|}
\hline Characteristic & $\begin{array}{c}\text { No. }(\%) \text { of patients } \\
n=19408\end{array}$ \\
\hline \multicolumn{2}{|l|}{ Sex } \\
\hline Female & $4879(25.1)$ \\
\hline \multicolumn{2}{|l|}{ Age group, yr } \\
\hline$<12$ & $420(2.2)$ \\
\hline $13-17$ & $881(4.5)$ \\
\hline $18-29$ & $4345(22.4)$ \\
\hline $30-49$ & $5569(28.7)$ \\
\hline $50-69$ & $4831(24.9)$ \\
\hline$\geq 70$ & $3362(17.3)$ \\
\hline \multicolumn{2}{|l|}{ Neighbourhood income quintile } \\
\hline 1 (lowest) & $4793(24.7)$ \\
\hline 2 & $4054(20.9)$ \\
\hline 3 & $3758(19.4)$ \\
\hline 4 & $3478(17.9)$ \\
\hline 5 (highest) & $3161(16.3)$ \\
\hline Missing & $164(0.8)$ \\
\hline \multicolumn{2}{|l|}{ Rurality* } \\
\hline Rural (population < 10000 ) & $4284(22.1)$ \\
\hline Urban (population > 10000 ) & $15112(77.9)$ \\
\hline \multicolumn{2}{|c|}{ Elixhauser Comorbidity Index total score } \\
\hline 0 & $15515(79.9)$ \\
\hline 1 & $1702(8.8)$ \\
\hline$\geq 2$ & $2191(11.3)$ \\
\hline \multicolumn{2}{|l|}{ Nature of injury } \\
\hline Accidental injury & $13250(68.3)$ \\
\hline Suicide & $4331(22.3)$ \\
\hline Homicide & $1827(9.41)$ \\
\hline \multicolumn{2}{|l|}{ Location of death } \\
\hline Out of hospital & $14089(72.6)$ \\
\hline Trauma centre & $2761(14.2)$ \\
\hline Non-trauma centre & $2558(13.2)$ \\
\hline
\end{tabular}

\section{Out-of-hospital versus in-hospital deaths}

The most common mechanisms of injury in the study population were motor vehicle collisions $(12065,62.2 \%)$, followed by gunshot wounds $(3134,16.1 \%)$ and falls (2387, $12.3 \%$; Table 2). The trends in mechanisms of injury were similar in patients who died out of hospital and in hospital, but we found a notably higher rate of deaths related to gunshot wounds that occurred in the out-of-hospital setting and a higher rate of deaths from motor vehicle collisions that occurred after admission to hospital (in-hospital deaths). Significantly more suicide-related deaths occurred in the out-of-hospital setting.
Overall, deaths were attributed most frequently to multiple body-system injuries (8986, 46.3\%), followed by traumatic brain injury $(7527,38.8 \%)$ and thoracic injuries $(3343,17.2 \%)$. Overall rates of injury diagnoses were similar between individuals who died without transport to hospital and those who died in hospital, but individuals who died in out-of-hospital settings had significantly higher rates of multiple body-system injuries and lower rates of injuries to the abdomen, pelvis or lumbar spine than patients who died in hospital.

\section{Trauma centre versus non-trauma centre deaths}

Patterns of injury were generally similar between patients who died at trauma centres and non-trauma centres (Table 3). Patients residing in rural locations were more likely to be treated at a non-trauma centre. Patients treated at nontrauma centres had higher Elixhauser Comorbidity Index scores, consistent with a greater number of medical comorbidities. Patients treated at trauma centres were more likely to have traumatic brain injuries but less likely to have fatal multiple body-system injuries, thoracic injuries or complications of an injury associated with their death. Patients who died at a trauma centre were significantly more likely to have at least 1 surgical intervention before their death.

\section{Interpretation}

In this large, population-based study, we describe the epidemiology of fatal injuries in Ontario, Canada. We found that most injury-related deaths occurred in the out-of-hospital setting, were accidental in nature and occurred in adult males who lived in urban areas of the province. Overall, the types, mechanisms and anatomic patterns of injury were consistent between in-hospital and out-of-hospital deaths and between trauma and non-trauma centres. Patients treated at non-trauma centres were more likely to live in rural areas of the province and significantly less likely to receive a surgical intervention before their death compared to patients managed at a designated trauma centre. These findings have implications for practising clinicians, public health officials and health policy-makers.

First, a disproportionate degree of trauma deaths in Ontario occurred in the out-of-hospital setting. Although this finding was similar to those of other recently published injury mortality studies, ${ }^{30}$ it could be interpreted several ways. One perspective would be that these patients were so severely injured that they were dying on scene and resuscitation efforts were being appropriately terminated in the field to avoid potentially dangerous "lights and sirens" transport by prehospital providers ${ }^{31}$ for further futile in-hospital resuscitation efforts.

Another view would be that this disproportionate burden of out-of-hospital deaths reflects suboptimally organized prehospital care in our system, and that a specialized physician-led prehospital trauma response team ${ }^{32-35}$ would reduce mortality, as has been found in other jurisdictions. ${ }^{32,35}$ Ultimately our study was not designed to answer that question, and the inability to access individual patient medical, autopsy and coroner's reports precludes any assessment of the preventability of any deaths with either different or more aggressive medical care. 


\begin{tabular}{|c|c|c|c|c|}
\hline \multirow[b]{2}{*}{ Characteristic } & \multicolumn{3}{|c|}{ No. $(\%)$ of patients* } & \multirow[b]{2}{*}{$\begin{array}{c}\text { Standardized } \\
\text { difference }\end{array}$} \\
\hline & $\begin{array}{c}\text { Total deaths } \\
n=19408\end{array}$ & $\begin{array}{c}\text { Out-of-hospital } \\
\text { deaths } \\
n=14089\end{array}$ & $\begin{array}{c}\text { In-hospital } \\
\text { deaths } \\
n=5319\end{array}$ & \\
\hline \multicolumn{5}{|l|}{ Demographic characteristics } \\
\hline Female & $4879(25.1)$ & $3448(24.5)$ & $1431(26.9)$ & 0.1 \\
\hline Age, yr, median (IQR) & $45(26-62)$ & $44(27-59)$ & $49(26-71)$ & 0.2 \\
\hline Rural residence & $4284(22.1)$ & $3234(23.0)$ & $1050(19.7)$ & 0.1 \\
\hline Elixhauser Comorbidity Index score, median (range) & $0(0-2)$ & $0(0-2)$ & $1(0-2)$ & 0.1 \\
\hline \multicolumn{5}{|l|}{ Mechanism of injury } \\
\hline Motor vehicle collision (all types) & $12065(62.2)$ & $8273(58.7)$ & $3792(71.3)$ & 0.3 \\
\hline Gunshot wound & $3134(16.1)$ & $2754(19.5)$ & $380(7.1)$ & 0.4 \\
\hline Fall & $2387(12.3)$ & $1736(12.3)$ & $651(12.2)$ & $<0.1$ \\
\hline Stabbing & $1135(5.8)$ & $855(6.1)$ & $280(5.3)$ & $<0.1$ \\
\hline Person struck $\ddagger$ & $687(3.5)$ & $471(3.3)$ & $216(4.1)$ & $<0.1$ \\
\hline \multicolumn{5}{|l|}{ Nature of injury } \\
\hline Suicide & $4331(22.3)$ & $3884(27.6)$ & $447(8.4)$ & 0.5 \\
\hline \multicolumn{5}{|l|}{ Injury diagnosis by body region§ } \\
\hline Multiple body-system & $8986(46.3)$ & $6816(48.4)$ & $2170(40.8)$ & 0.1 \\
\hline Traumatic brainף & $7527(38.8)$ & $5275(37.4)$ & $2252(42.3)$ & $<0.1$ \\
\hline Thoracic & $3343(17.2)$ & $2351(16.7)$ & $992(18.7)$ & 0.1 \\
\hline Neck and cervical spine & $1334(6.9)$ & $975(6.9)$ & $359(6.7)$ & 0.2 \\
\hline Abdomen, lower back, lumbar spine and pelvis & $1137(5.9)$ & $684(4.9)$ & $453(8.5)$ & 0.2 \\
\hline Limb & $409(2.1)$ & $248(1.8)$ & $161(3.0)$ & 0.1 \\
\hline Complications and sequelae of injuries & $274(1.4)$ & $167(1.2)$ & $107(2.0)$ & 0.1 \\
\hline \multicolumn{5}{|c|}{$\begin{array}{l}\text { Note: IQR = interquartile range. } \\
\text { *Unless stated otherwise. } \\
\text { †Standardized difference }>0.1 \text { indicates a statistically significant difference between groups. } \\
\text { †lncludes diagnoses involving persons struck by other persons or various objects. } \\
\text { §Some people had injuries in more than } 1 \text { body region. } \\
\text { ๆIncludes head, brain and facial injuries. }\end{array}$} \\
\hline
\end{tabular}

From a trauma-system perspective, we found that patients who died in rural regions of Ontario were less likely to be treated at a trauma centre. Previous work has shown that although $85 \%$ of Ontarians live within 1 hour of a trauma centre, trauma deaths are twice as common in rural areas of Ontario. ${ }^{36}$ Injury profiles of patients who died at non-trauma centres were generally similar to those of patients who died at trauma centres, with the exceptions of a notably higher rates of thoracic injuries and lower rates of traumatic brain injuries in patients treated in non-trauma centres. These findings could have been because thoracic injuries are fatal earlier on than brain injuries, or they could have been driven by more limited clinical experience in managing major thoracic injury outside of trauma centres.

Rates of surgical intervention were significantly higher for patients managed at trauma centres than at non-trauma centres. Most likely, this finding relates to access to trauma surgeons at trauma centres and critically injured patients arriv- ing early enough in their clinical course to warrant a trial of operative therapy despite the patient's severe injury burden. However, it is also possible that a referral bias exists in our system and contributes to these findings; that is, critically injured patients with nonoperable injuries are not transferred from a non-trauma centre to a trauma centre and die at the primary centre, whereas patients with 1 or more injuries amenable to a surgical intervention are accepted in transfer by the trauma centre, undergo a procedure and still die, but contribute to the high rate of operative interventions in patients who die at a trauma centre.

For the clinician at the bedside, our data confirm that the most common injury patterns in patients with trauma who arrive in cardiac arrest or near-arrest states are multiple bodysystem injury, brain or chest injuries. Targeted interventions to address airway obstruction, obstructive shock and hypovolemia are most likely to restore spontaneous circulation in these patients and should be prioritized..$^{33,34}$ 


\begin{tabular}{|c|c|c|c|c|}
\hline \multirow[b]{2}{*}{ Characteristic } & \multicolumn{3}{|c|}{ No. $(\%)$ of patients* } & \multirow[b]{2}{*}{$\begin{array}{c}\text { Standardized } \\
\text { difference† }\end{array}$} \\
\hline & $\begin{array}{c}\text { All in-hospital } \\
n=5319\end{array}$ & $\begin{array}{c}\text { Trauma centre } \\
n=2761\end{array}$ & $\begin{array}{l}\text { Non-trauma } \\
\text { centre } \\
n=2558\end{array}$ & \\
\hline \multicolumn{5}{|l|}{ Demographics } \\
\hline Female & $1431(26.9)$ & $735(26.6)$ & $696(27.2)$ & $<0.1$ \\
\hline Age, yr, median (IQR) & $49(26-71)$ & $51(27-72)$ & $48(26-69)$ & 0.1 \\
\hline Rural residence & $1050(19.7)$ & $445(16.1)$ & $605(23.7)$ & 0.2 \\
\hline Elixhauser Comorbidity Index score, median (range) & $1(0-2)$ & $0(0-2)$ & $1(0-2)$ & 0.3 \\
\hline \multicolumn{5}{|l|}{ Mechanism of injury } \\
\hline Motor vehicle collision (all types) & $3792(71.3)$ & $1945(70.4)$ & $1847(72.2)$ & $<0.1$ \\
\hline Fall & $651(12.2)$ & $372(13.5)$ & $279(10.9)$ & 0.1 \\
\hline Gunshot wound & $380(7.1)$ & $207(7.5)$ & $173(6.8)$ & $<0.1$ \\
\hline Stabbing & $280(5.3)$ & $113(4.1)$ & $167(6.5)$ & 0.1 \\
\hline Person struck $\ddagger$ & $216(4.1)$ & $124(4.5)$ & $92(3.6)$ & 0.1 \\
\hline \multicolumn{5}{|l|}{ Injury diagnoses } \\
\hline Traumatic brain§ & $2252(42.3)$ & $1394(50.5)$ & $858(33.5)$ & 0.4 \\
\hline Multiple body-system & $2170(40.8)$ & $1056(38.2)$ & $1114(43.5)$ & 0.1 \\
\hline Thoracic & $992(18.7)$ & $346(12.5)$ & $646(25.3)$ & 0.3 \\
\hline Abdomen, lower back, lumbar spine and pelvis & $453(8.5)$ & $227(8.2)$ & $226(8.8)$ & $<0.1$ \\
\hline Neck and cervical spine & $359(6.7)$ & $176(6.4)$ & $183(7.2)$ & $<0.1$ \\
\hline Limb & $161(3.0)$ & $75(2.7)$ & $86(3.4)$ & $<0.1$ \\
\hline Complications and sequalae of injuries & $107(2.0)$ & $40(1.4)$ & $67(2.6)$ & 0.1 \\
\hline \multicolumn{5}{|l|}{ Surgical interventions } \\
\hline Any surgical & $963(18.1)$ & $851(30.8)$ & $112(4.4)$ & 0.6 \\
\hline Neurosurgical & $434(8.2)$ & $406(14.7)$ & $28(1.1)$ & 0.4 \\
\hline General surgical & $305(5.7)$ & $269(9.7)$ & $36(1.4)$ & 0.1 \\
\hline Cardiothoracic & $202(3.8)$ & $156(5.7)$ & $46(1.8)$ & 0.5 \\
\hline Orthopedic surgery & $174(3.3)$ & $163(5.9)$ & $11(0.4)$ & 0.2 \\
\hline $\begin{array}{l}\text { Note: IQR = interquartile range. } \\
\text { *Unless stated otherwise. } \\
\text { †Standardized difference }>0.1 \text { indicates a statistically significant diffe } \\
\text { †Includes diagnoses involving persons struck by other persons or va } \\
\text { §Includes head, brain and facial injuries. }\end{array}$ & $\begin{array}{l}\text { tween groups. } \\
\text { ts. }\end{array}$ & & & \\
\hline
\end{tabular}

Health policy-makers should take note of the disproportionate burden of trauma deaths that occur in the out-ofhospital setting and consider whether our current prehospital system is appropriately resourced to triage, treat and transport major trauma cases. Similarly, the near-equal distribution of injury deaths between trauma and non-trauma centres suggests there are opportunities to improve prehospital triage of major trauma cases to trauma centres, or otherwise improve access to potentially life-saving surgical interventions.

\section{Limitations}

There were some limitations to our study design, several of which have already been noted. The most important is that the trade-off for population-level data is the loss of granularity associated with chart-level data abstraction. Our study generated many questions about the mechanisms of injury, types of injuries and treatments received by our study population, including how preventable some deaths may have been, but these questions could not be answered using population-level data sets. Similarly, because most of the databases we used were not designed with injury research in mind, many variables were not available to us that would have provided greater insight into the timing, circumstances and clinical context of death. The reliability of identifying cause of death from death certificates (via the ORGD) was also largely unknown. However, internal validity studies at ICES indicate that for suicide-related deaths (many of which would be due to injuries), this data set has high sensitivity (range $84.3 \%$ to 
$96.8 \%$, depending on the year of study), compared with the gold standard of coroner's records. ${ }^{37}$

\section{Conclusion}

Most injury deaths in Ontario occur in the prehospital setting or are managed at non-trauma centres, and many patients receive no surgical intervention before death. There are likely opportunities to improve access to specialized injury care in Ontario's trauma system through advanced prehospital resuscitative care, better integration of non-trauma centres in the system and improved access to potentially life-saving surgical interventions for patients who are initially managed at a non-trauma centre.

\section{References}

1. National Trauma Registry 2009 report: Major injury in Canada (includes 20072008 data). Ottawa: Canadian Institute for Health Information; 2010.

2. Krug EG. Injury: a leading cause of the global burden of disease. Geneva: World Health Organization; 1999.

3. Stiell IG, Nesbitt LP, Pickett W, et al.; OPALS Study Group. The OPALS Major Trauma Study: impact of advanced life-support on survival and morbidity. CMA7 2008;178:1141-52.

4. Evans CCD, DeWit Y, Seitz D, et al. Mental health outcomes after major trauma in Ontario: a population-based analysis. CMA7 2018;190:E1319-27.

5. Jacoby SF, Rich JA, Webster JL, et al. "Sharing things with people that I don't even know": help-seeking for psychological symptoms in injured Black men in Philadelphia. Ethn Health 2020;25:777-95.

6. Zatzick DF, Rowhani-Rahbar A, Wang J, et al. The cumulative burden of mental, substance use, and general medical disorders and rehospitalization and mortality after an injury. Psychiatr Serv 2017;68:596-602.

7. Lendrum RA, Lockey DJ. Trauma system development. Anaesthesia 2013; 68(Suppl 1):30-9.

8. Evans DC. From trauma care to injury control: a people's history of the evolution of trauma systems in Canada. Can 7 Surg 2007;50:364-9.

9. Kortbeek JB, Buckley R. Trauma-care systems in Canada. Injury 2003; 34:658-63.

10. Trauma system accreditation guidelines. 4th rev. Halifax (NS): Trauma Association of Canada; 2011. Available: www.traumacanada.org/wp-content/ uploads/2019/05/Accreditation_Guidelines_2011.pdf (accessed 2020 Nov. 20).

11. Drake SA, Holcomb JB, Yang Y, et al. Establishing a regional trauma preventable/potentially preventable death rate. Ann Surg 2020;271:375-82.

12. Carroll SL, Dye DW, Smedley WA, et al. Early and prehospital trauma deaths: who might benefit from advanced resuscitative care? 7 Trauma Acute Care Surg 2020;88:776-82.

13. Maghami S, Hendrix C, Matecki M, et al. Comparison of the causes of death and wounding patterns in urban firearm-related violence and civilian public mass shooting events. 7 Trauma Acute Care Surg 2020;88:310-3.

14. Callcut RA, Kornblith LZ, Conroy AS, et al.; Western Trauma Association Multicenter Study Group. The why and how our trauma patients die: a prospective Multicenter Western Trauma Association study. 7 Trauma Acute Care Surg 2019;86:864-70.

15. Ontario demographic quarterly: highlights of first quarter 2020. Toronto: Government of Ontario; 2020. Available: www.ontario.ca/page/ontario -demographic-quarterly-highlights-first-quarter-2020 (accessed 2020 Nov. 15).

16. About Ontario. Toronto: Government of Ontario; 2012, updated 2019 Mar. 7. Available: www.ontario.ca/page/about-ontario\#section-0 (accessed 2020 Nov. 20).

17. Chiu M, Lebenbaum M, Lam K, et al. Describing the linkages of the immigration, refugees and citizenship Canada permanent resident data and vital statistics death registry to Ontario's administrative health database. BMC Med Inform Decis Mak 2016;16:135.

18. Raza S, Thiruchelvam D, Redelmeier DA. Death and long-term disability after gun injury: a cohort analysis. CMA7 Open 2020;8:E469-78.

19. Macpherson A, Schull MJ. Penetrating trauma in Ontario emergency departments: a population-based study. CFEM 2007;9:16-20.

20. Pincus D, Wasserstein D, Nathens AB, et al. Direct medical costs of motorcycle crashes in Ontario. CMA7 2017;189:E1410-5.

21. LeMier M, Cummings P, West TA. Accuracy of external cause of injury codes reported in Washington State hospital discharge records. Inj Prev 2001;7:334-8.

22. Altoijry A, Al-Omran M, Lindsay TF, et al. Validity of vascular trauma codes at major trauma centres. Can 7 Surg 2013;56:405-8.

23. National Center for Health Statistics. ICD injury matrices. Atlanta: Centers for Disease Control and Prevention; 2015. Available: www.cdc.gov/nchs/ injury/injury_matrices.htm (accessed 2020 Nov. 15).

24. Kralj B. Measuring "rurality" for purposes of health-care planning: an empirical measure for Ontario. Ont Med Rev 2000;67:33-52.
25. Austin PC, Stanbrook MB, Anderson GM, et al. Comparative ability of comorbidity classification methods for administrative data to predict outcomes in patients with chronic obstructive pulmonary disease. Ann Epidemiol 2012;22:881-7.

26. Brewer N, Borman B, Sarfati D, et al. Does comorbidity explain the ethnic inequalities in cervical cancer survival in New Zealand? A retrospective cohort study. BMC Cancer 2011;11:132.

27. Elixhauser A, Steiner C, Harris DR, et al. Comorbidity measures for use with administrative data. Med Care 1998;36:8-27.

28. Austin PC. Using the standardized difference to compare the prevalence of a binary variable between two groups in observational research. Commun Stat Simul Comput 2009;38:1228-34.

29. Yang D, Dalton JE. A unified approach to measuring the effect size between two groups using SAS [abstract]. SAS Global Forum 2012; 2012 Apr. 22-25; Orlando (FL).

30. Gunst M, Ghaemmaghami V, Gruszecki A, et al. Changing epidemiology of trauma deaths leads to a bimodal distribution. Proc Bayl Univ Med Cent 2010;23:349-54.

31. Watanabe BL, Patterson GS, Kempema JM, et al. Is use of warning lights and sirens associated with increased risk of ambulance crashes? A contemporary analysis using national EMS Information System (NEMSIS) data. Ann Emerg Med 2019;74:101-9.

32. Fukuda T, Ohashi-Fukuda N, Kondo Y, et al. Association of prehospital advanced life support by physician with survival after out-of-hospital cardiac arrest with blunt trauma following traffic collisions: Japanese registry-based study. FAMA Surg 2018;153:e180674.

33. Lockey DJ, Lyon RM, Davies GE. Development of a simple algorithm to guide the effective management of traumatic cardiac arrest. Resuscitation 2013;84:738-42.

34. Sherren PB, Reid C, Habig K, et al. Algorithm for the resuscitation of traumatic cardiac arrest patients in a physician-staffed helicopter emergency medical service. Crit Care 2013;17:308.

35. Knapp J, Häske D, Böttiger BW, et al. Influence of prehospital physician presence on survival after severe trauma: systematic review and meta-analysis. 7 Trauma Acute Care Surg 2019;87:978-89.

36. Gomez D, Berube M, Xiong W, et al. Identifying targets for potential interventions to reduce rural trauma deaths: a population-based analysis. $f$ Trauma 2010;69:633-9.

37. Gatov E, Kurdyak P, Sinyor M, et al. Comparison of vital statistics definitions of suicide against a coroner reference standard: a population-based linkage study. Can F Psychiatry 2018;63:152-60.

Affiliations: Department of Emergency Medicine (Evans), Queen's University; ICES Queen's (Evans, Li), Kingston, Ont.; Department of Psychiatry (Seitz), University of Calgary, Calgary, Alta.

Contributors: Chris Evans conceived the study. Wenbin Li performed the data analyses. All authors contributed to the design of the study, wrote the manuscript, revised it critically for important intellectual content, gave final approval of the version to be published and agreed to be accountable for all aspects of the work.

Funding: There is no specific funding support associated with this study.

Content licence: This is an Open Access article distributed in accordance with the terms of the Creative Commons Attribution (CC BY-NCND 4.0) licence, which permits use, distribution and reproduction in any medium, provided that the original publication is properly cited, the use is noncommercial (i.e., research or educational use), and no modifications or adaptations are made. See: https://creativecommons.org/licenses/ by-nc-nd/4.0/

Data sharing: All data can be shared with researchers subject to ICES Queen's policies and approval.

Supplemental information: For reviewer comments and the original submission of this manuscript, please see www.cmajopen.ca/content/9/1/ E208/suppl/DC1.

Disclaimer: Parts of this material are based on data or information compiled and provided by the Canadian Institute for Health Information (CIHI). However, the analyses, conclusions, opinions and statements expressed in the material are those of the authors, and not necessarily those of CIHI. In addition, this study was supported by ICES, which is funded by an annual grant from the Ontario Ministry of Health and Long-Term Care. The opinions, results and conclusions reported in this paper are those of the authors and are independent from the funding sources. No endorsement by ICES or the Ontario Ministry of Health is intended or should be inferred. 